\title{
DEBATE: LOS SUEÑOS Y CONFLICTOS DEL CHILE DE LA UNIDAD POPULAR
}

\author{
Jorge Arrate Mac Niven, Maria Isabel Matamala Vivaldi, \\ Verónica Valdivia Ortiz de Zárate y Peter Winn
}




\title{
DEBATE: LOS SUEÑOS Y CONFLICTOS DEL CHILE DE LA UNIDAD POPULAR ${ }^{1}$
}

\author{
Jorge Arrate Mac Niven, Maria Isabel Matamala Vivaldi, \\ Verónica Valdivia Ortiz de Zárate y Peter Winn
}

\section{Modera: Francisco Figueroa Cerda}

Svenska Arensburg: les damos la más cordial bienvenida al conversatorio "Los sueños y conflictos del Chile de la Unidad Popular", organizado por la Vicerrectoría de Extensión y Comunicaciones y auspiciado por la Revista Anales de la Universidad de Chile. Colabora en esta actividad la Fundación Víctor Jara y la Radio Universidad de Chile. La conversación de hoy es la segunda instancia de un ciclo dedicado a conmemorar el triunfo histórico de Salvador Allende y el ascenso del gobierno de la UP el 4 de septiembre de 1970. Agradecemos la presencia de las y los invitados que nos acompañan hoy: Peter Winn, Verónica Valdivia, María Isabel Matamala y Jorge Arrate. Bienvenidos y bienvenidas y muchas gracias por aceptar esta invitación. Conducirá esta conversación Francisco Figueroa, periodista de la Universidad de Chile y Magíster en Cultura y Sociedad de la London School of Economics, editor de la revista Palabra Publica y autor del libro Llegamos para quedarnos: crónicas de la revuelta estudiantil.

Francisco Figueroa: muchas gracias, Svenska. Para abrir este conversatorio, lo primero que quisiera hacer es presentar a nuestros invitados e invitadas. Nos acompaña Peter Winn, profesor titular de Historia de América Latina de la Universidad de Tufts en Boston, Estados Unidos, y autor, entre otros libros, de La revolución chilena y Tejedores de la revolución: los trabajadores de Yarur y la vía chilena al socialismo, volumen con el cual ayudó a restituir el lugar del movimiento popular y obrero en la historiografía sobre la UP y a la comprensión de la dimensión social de los conflictos que la cruzaron.

Nos acompaña también Verónica Valdivia, historiadora y profesora titular de la Universidad Diego Portales, quien también ha hecho una contribución notable estudiando el papel de las derechas, de las Fuerzas Armadas y el nacionalismo en

1. Este debate se realizó el miércoles 9 de septiembre de 2020, a través de una transmisión en línea de la Vicerrectoría de Extensión y Comunicaciones de la Universidad de Chile. 
la historia política chilena. Entre sus obras se encuentran Nacionales y gremialistas: el "parto" de la politica chilena 1964-1973; Subversión, cohesión y consenso: creando el Chile del siglo XX (1918, 1938); y El golpe después del golpe: Leigh versus Pinochet. Chile 1960-1980.

Recibimos también a María Isabel Matamala, médica cirujana especialista en salud pública y género. Feminista de destacada trayectoria, fue militante del MIR desde 1967 y también sobreviviente de la represión de la dictadura. Ha trabajado en el Observatorio de Equidad de Género, fundó la Red de Salud de las Mujeres Latinoamericanas y del Caribe y fue encargada del área de género del Ministerio de Salud del primer gobierno de Michelle Bachelet, mismo cargo que ocupó en la Organización Panamericana de la Salud.

Finalmente, agradecemos la presencia de Jorge Arrate, abogado, economista, escritor y político de dilatada trayectoria. Fue ministro de Estado de los presidentes Patricio Aylwin, Eduardo Frei Ruiz-Tagle y, por supuesto, Salvador Allende. Presidió el Partido Socialista (PS), ha sido candidato presidencial y es el autor de numerosos libros, entre los cuales destacamos Memoria de la izquierda chilena: 1970-2000, en coautoría con Eduardo Rojas; Pasión y razón del socialismo cbileno; La fuerza democrática de la idea socialista; y sus memorias Con viento a favor.

Para comenzar, quisiera introducir con esta pregunta: ¿cuáles eran las aspiraciones de ese Chile que tuvo a la UP como gobierno? Quisiera partir ofreciéndole la palabra a Peter Winn, quien, en los años 1972 y 1973, estuvo en Chile estudiando muy de cerca la experiencia de la UP.

Peter Winn: quiero agradecer la invitación a participar en este panel y subrayo la experiencia de la UP, que por muchos años fue memoria prohibida en Chile y que hoy se reconoce como una época clave para la historia reciente y la memoria chilena. Creo que la mayor aspiración era la vía chilena al socialismo, el sueño de Allende de conducir a un Chile socialista por la vía pacífica. Porque me dijo, en una entrevista de 1972: hay millones de personas en el mundo que quisieran llegar al socialismo, pero sin tener que pasar por una guerra civil. Ese camino supuso la nacionalización de las riquezas básicas de Chile, sus minas de cobre, lo que Allende llamó "el sueldo de Chile", y una reforma agraria profunda, así como la estatización de los bancos y monopolios. También se propusieron cambios estructurales para resolver los problemas que ni el gobierno derechista de Alessandri ni el gobierno reformista de Frei habían sido capaces de abordar: la dependencia económica, la estanflación, un déficit de 500 mil viviendas, falta de participación política adecuada. En el caso de los trabajadores de las grandes empresas, como Yarur, tenían aspiraciones muy concretas: estatizar sus industrias y dar participación a los trabajadores en la administración de la empresa. Además, en ese camino hacia el socialismo democrático, Allende prometió satisfacer las necesidades básicas del 
pueblo, entre ellas, trabajo para todos, vivienda digna, medicina gratuita y leche para todos los niños de Chile. Todo esto se materializaba en las cuarenta medidas inmediatas para el gobierno de Allende. En resumen, la aspiración principal del pueblo era una "revolución con empanadas y vino tinto", como prometió Allende. Es decir, una revolución sin sacrificio. Y Allende cumplió, con un aumento del 30 por ciento de los ingresos familiares en el primer año del gobierno de la UP. Me acuerdo que muchos campesinos tuvieron bajo la UP por primera vez los recursos personales para acceder a cosas tan básicas como una cama para dormir o sábanas para cubrirse, cosas que hasta entonces no habían estado a su alcance. El pueblo participó así en lo que se llamó "las fiestas del consumo de 1971” y esa sí fue una revolución.

Constaté con mis propios ojos cómo los sueños revolucionarios de la UP inspiraron a los trabajadores de Yarur, una empresa con dos mil trabajadores. La victoria de Allende animó a los obreros de Yarur a luchar por un sindicato independiente y, cuando los Yarur se negaron a reconocer a los dirigentes elegidos por los trabajadores y a sentarse a conversar y negociar con ellos, los obreros se tomaron la fábrica y le reclamaron a Allende que cumpliera lo prometido en campaña: estatizar su industria. Ya muchos chilenos se habían tomado la revolución en sus propias manos y estaban cumpliendo sus sueños. Para ellos, la promesa de Allende de que nunca reprimiría al pueblo significaba una luz verde para los pobladores sin casa, para los campesinos sin tierra y para los trabajadores industriales. Ya cientos de miles de pobladores habían conseguido sus viviendas tomando sitios en los alrededores de las ciudades y exigiendo al gobierno una vivienda digna, con luz eléctrica y agua potable. En el año 1972, uno de cada seis habitantes de Santiago vivía en un campamento producto de una toma y estaba en camino de cumplir su sueño de tener una casa digna. Para esas fechas, miles de campesinos se habían tomado los fundos que trabajaban y habitaban, presionando al gobierno de la UP para que los expropiara y cumpliera con la promesa de una reforma agraria profunda. Esta revolución rural desde abajo logró que la reforma agraria terminara con los latifundios de Chile en solo 18 meses en vez de en seis años, como estaba previsto. Las tomas de sitios para formar campamentos eran ya comunes en los años sesenta, las tomas de fundos eran menos comunes, pero formaban parte de la experiencia chilena. Sin embargo, la toma de fábricas casi no se conocía. Los trabajadores de Yarur, entonces, fueron pioneros de un nuevo camino revolucionario.

Francisco Figueroa: gracias, Peter. A raíz de tu respuesta, quiero pasarte la palabra a ti, Verónica, para que nos cuentes, desde tu perspectiva, cuáles eran las aspiraciones del gobierno chileno, cuán novedosas fueron, cuánto tuvieron que avanzar para ser gobierno. 
Verónica Valdivia: reitero los agradecimientos por la iniciativa y la invitación. Yo creo que la principal aspiración de quienes plantearon la UP, en primer lugar, era hacer la modernización enfrentando el atraso que el país tenía, y ese era un desafío ineludible para 1970, porque durante todo el siglo XX el Estado chileno tuvo que, de alguna manera, suplir la falta de modernización, haciéndose cargo, dentro de las posibilidades que los acuerdos políticos permitían, de algunas de las necesidades de los sectores populares. Desde 1938, e incluso podríamos tomar la dictadura de Ibáñez (1927-1931), pero desde 1938, con Pedro Aguirre Cerda y los gobiernos del Frente Popular, el Estado asumió la tarea de hacerse cargo de las grandes necesidades que los sectores populares tenían. A pesar de que un importante segmento de ellos quedó al margen, no fueron integrados, porque la legislación social que se aprobó en el Código del Trabajo solo reconocía a los obreros sindicalizados y, por tanto, a los grupos que estaban en las áreas económicas más importantes. Por eso es que muchos libros hacen una crítica a los gobiernos del Frente Popular y sostienen que estos distinguían entre asegurados, o sea, quienes pertenecían a un sindicato y al seguro obrero obligatorio, e indigentes, y que el Estado chileno se desentendió de los indigentes para hacerse cargo solamente de los que tenían protección legal.

En realidad, eso no era así: desde 1938 hubo una preocupación muy, muy grande por hacerse cargo de la gente pobre, a la cual no le llegaban las leyes, y el Estado invirtió mucho en ayuda, en pan, techo y abrigo, aunque legalmente carecían de derechos. Se utilizaron muchos mecanismos, el Ministerio de Higiene, el cual después se transformó en el Ministerio de Salud, y distintos organismos del Estado para que los sectores de menores recursos pudieran satisfacer alguna parte de sus necesidades mínimas. Esas políticas muchas veces adquirieron la forma de beneficencia, porque en muchos casos era con la ayuda de privados. En la práctica, era el Estado y el gobierno frentepopulista el que tenía el mayor interés en que el Estado llegara a las/los carentes de derechos. En ese proceso, las primeras damas cumplieron un rol fundamental: Juanita Aguirre; Marta Ide, esposa de Juan Antonio Ríos; Rosa "Miti” Markmann, esposa de Gabriel González; la esposa de Carlos Ibáñez, Graciela Letelier. A pesar de que muchas de ellas tenían visiones muy conservadoras en materia de género, las primeras damas del periodo que yo menciono, hasta el 58, fueron un brazo social del Estado fundamental para llegar con apoyo social a un amplio espectro de sectores populares desde 1938.

Esas ayudas, por supuesto que eran limitadas y siempre tenían el sello de gobiernos de clase media que estaban apoyando a los sectores populares. Yo creo que el gran cambio, con la UP y Salvador Allende, fue que los sectores populares comprendieron que Allende representaba los intereses populares y que le iba a imprimir un sello popular a su gobierno y a ampliar muchas de estas facultades, que habían tenido en algún momento un carácter benéfico, para transformarlas en 
derechos. Creo que hubo un gran esfuerzo del Estado por hacer de los derechos ciudadanos una realidad.

Francisco Figueroa: muchas gracias, Verónica. María Isabel, ¿cómo lo viste desde tu experiencia militando en una izquierda que participaba, precisamente, en estas contradicciones, con distintas tesis acerca de cómo organizar ese protagonismo popular que el golpe terminó derribando?

María Isabel Matamala: desde comienzos del siglo XX se había venido produciendo una síntesis de aspiraciones en las diversas luchas y conflictos que discurrían en la profundidad del Chile popular, que forjó a miles de dirigentes sociales. En el contexto de la Guerra Fría, la larga década de los sesenta empujó la radicalización de los proyectos gubernamentales, por una parte, y la ideologización creciente de las fuerzas políticas, por otra. La izquierda se fortaleció en medio de la movilización y articulación social, incluso durante el proyecto reformista del gobierno de Frei, que también otorgó, sin quererlo, las condiciones para la formación de una expresión de las nuevas izquierdas latinoamericanas, como el MIR, que a su vez contribuyó a una mayor radicalización de fuerzas sociales y políticas desde la segunda mitad de la década.

En ese contexto de un continuo de luchas, las aspiraciones del pueblo a nivel nacional podemos sintetizarlas en tres ámbitos, a mi juicio: primero, resolver las necesidades socioeconómicas que golpeaban sus condiciones de vida, su bienestar y su dignidad. Las mujeres que se habían incorporado a la vida ciudadana activa hacía solo dos décadas con la conquista del derecho a voto, y que habían fortalecido su organización en el campo y las zonas urbanas, aspiraban a un bienestar familiar y comunitario que asegurara terminar con la mortalidad infantil, con la propia mortalidad por aborto, así como mejores condiciones de trabajo y de vida. Segundo, terminar con la injusticia social, transitando de un modelo capitalista a un socialismo "a la chilena", democrático y participativo. Esto suponía una tremenda transformación estructural, inédita por la vía pacífica. En tercer lugar, la indignación y rechazo ante situaciones de la contingencia nacional, como la enorme desigualdad salarial, la indiferencia, el racismo, el clasismo por parte de los sectores empresariales, así como diversas expresiones de corrupción que empezaban a emerger públicamente.

Toda esta subjetividad colectiva de aspiraciones de cambios era estimulada por experiencias motivadoras, como la revolución cubana, el 1968 en el mundo, incluido Tlatelolco y las gestas del Che; las luchas descolonizadoras de África y Asia. Todo ello proporcionaba esperanzas a través de la prometedora propuesta de un proyecto político compartido por diversos partidos de izquierda y populares. Había un horizonte, era el socialismo; había un programa, cuarenta medidas que 
resolverían las necesidades más acuciantes; había un candidato, luego compañero presidente, que además de su propuesta política era capaz de conectarse y de trasmitir emocionalmente su compromiso con el pueblo. Era un compromiso construido no solo por su vinculación con la teoría marxista, sino que también desde su experiencia concreta en su vida como político y como médico de salud pública y medicina social. De esta forma, la UP fue la expresión de las energías acumuladas por más de medio siglo, con un programa de reformas que agredía intereses y producía miedo y odio en la derecha nacional, polarizando las alternativas de modernización del Chile de entonces.

Francisco Figueroa: muchas gracias, María Isabel. Ahora vamos con Jorge. ¿Cuál es ese Chile que eligió a la UP como gobierno? ¿Cuáles eran sus aspiraciones y cómo te tocó a ti vivirlo como uno más de los protagonistas?

Jorge Arrate: primero, mis agradecimientos por la invitación a este foro en mi querida Universidad de Chile. Creo que el proceso que culminó el 4 de septiembre de 1970 con el triunfo de la UP, como han señalado aquí quienes me han antecedido, fue un proceso largo que se gestó en un periodo difícil, complejo, de maduración de las luchas populares y que, por ponerle un momento, yo diría que comenzó a fines del siglo XIX, a comienzos del siglo XX, con la figura emocionante de Luis Emilio Recabarren y su significado para las dos grandes corrientes del pensamiento popular chileno que se constituyeron en las dos décadas siguientes. No dejo afuera a otras vertientes a las que hay que reconocer, sin ninguna duda, como lo era el anarcosindicalismo, los libertarios, pero en verdad fue la corriente socialista la que recogió esas visiones. Yo creo que fue un periodo de muchas disputas, de muchos ires y venires, de avances y retrocesos. No fue un avance constante y fácil, pero se alcanzó un punto decisivo, después de momentos de diferencias verdaderamente fratricidas, a partir de los años cincuenta, cuando fue la primera candidatura de Allende, con la fundación de la Central Única de Trabajadores.

Ahí comenzaron esas dos décadas virtuosas en la historia de la izquierda chilena del siglo XX. Tuvieron características muy importantes. En primer lugar, nunca abandonaron lo que había sido una constante desde Recabarren y los anarcosindicalistas, que es una vinculación entre lo que hoy llamamos lo político y lo social. Hoy escuchamos todos los días decir que hay un abismo entre los partidos políticos y las luchas sociales, que no se vio un solo cartel de los partidos políticos en el 18-O. Bueno, en el movimiento popular chileno, como lo llamábamos en el siglo XX, esto era insólito, hubiera sido inusitado. Había una amalgama — con roces, por supuesto, nada es un calce perfecto, ¿no?-, en lo básico nadie hacía política si no era fundamentado en esta amalgama que era el movimiento popular en todas 
sus dimensiones, y que conducían los partidos políticos, eso hay que decirlo. Nadie ponía en duda que la conducción política la llevaban los partidos en esa época. Ese movimiento popular tuvo, además, la extraordinaria virtud, ya en los años cincuenta, de lograr manejar las diferencias, porque no se trataba de suprimirlas. Desde ya, creo en algo que he denominado, no sé si bien o mal, la "biodiversidad de la izquierda". La izquierda es una masa que, para sobrevivir, necesita una cierta diversidad que tiene que ser respetada, no puede ser arrasada, y cuando eso ha ocurrido, ha llevado a resultados catastróficos.

El camino es ser capaces de convivir en esas diferencias, entender que esas diferencias enriquecen, en una gran medida, lo que es un proyecto transformador. Creo que eso lo entendió la izquierda chilena a partir de los cincuenta y, particularmente, quien lo entendió y lo enseñó y lo explicó y lo repitió fue Allende. Incluso después de los sesenta surgieron, como recordaba María Isabel, otras corrientes en la izquierda del siglo XX más inspiradas en la revolución cubana, que no correspondían a estas dos corrientes ni tampoco a la corriente cristiana revolucionaria que también se desarrolló en los años sesenta. Pero, incluso en ese caso, la izquierda chilena nunca cayó en actitudes represivas. Las diferencias que hubo entre la UP y el MIR, se manejaron de una forma que permitió procesarlas sin que eso provocara un daño en este proceso transformador. Fue un movimiento popular que se identificó con la justicia, con la libertad, con la igualdad, con la solidaridad, con la dignidad, con contenidos chilenos, nacionales, porque tanto Recabarren como Allende fueron figuras con miradas fuertemente plantadas en lo que era la realidad chilena y latinoamericana, y fue un movimiento que nunca perdió, a través de todo este tiempo, el sentido clasista que lo había marcado desde sus inicios. Yo diría que su gran aspiración, y aquí termino, fue liberar el territorio, liberar el suelo chileno del dominio extranjero, liberar el suelo chileno de los oligarcas de la agricultura y liberar los cuerpos, los cuerpos de los trabajadores, de la explotación, de un capitalismo que tenía características muy salvajes.

Francisco Figueroa: Esa liberación del territorio a la que alude Jorge, sin duda se enfrentó no solo con injusticias salvajes, sino también con una oposición salvaje. Verónica, ayúdanos a comprender: ¿cuáles eran esos intereses?, ¿cómo se enfrentaron a la UP?

Verónica Valdivia: creo que hay que pensar en dos cosas fundamentales. Lo primero es que el sistema político chileno estaba preparado para impedir que un gobierno marxista pudiera triunfar, existían bloqueos institucionales que estaban deliberadamente puestos ahí para aceptar la presencia de la izquierda marxista en el sistema político, pero nunca en el gobierno, lo cual se tradujo en leyes de seguridad 
interior del Estado. Igualmente, las limitaciones que se le pusieron a la izquierda durante muchas décadas para desarrollar actividad política en el campo. Aunque ahora los estudios han demostrado que el PS y el PC tuvieron alguna presencia en las áreas campesinas antes de la reforma agraria, era una presencia menor, porque el sistema político estaba bloqueado por la mantención del latifundio y el control que los terratenientes tenían sobre el campesinado. Había una serie de dispositivos dentro del sistema que eran institucionales y que también eran, de alguna manera, fruto de un cierto acuerdo político tácito para que la izquierda no llegara al gobierno. Aunque la izquierda se unificó en el Frente de Acción Popular en 1956 y reafirmó su vía pacífica, la derecha y el centro siempre tuvieron claro que la izquierda era una especie de colaborador, pero no quien llevaba la iniciativa. En ese sentido, la posibilidad de que Allende triunfara era un imposible. Sin embargo, lo imposible sucedió. ¿Por qué? Porque, finalmente, el último recurso que tuvieron siempre para impedir el protagonismo de las izquierdas -partidos y sindicatos- fueron las Fuerzas Armadas. Cada vez que había una huelga muy grande, decretaban zona de emergencia, había jefes militares que sometían a la zona y la pacificaban; el Ejecutivo siempre tuvo el instrumento de la fuerza y de la inteligencia, Carabineros e Investigaciones, para neutralizar un poder desbordante desde la izquierda. Pero, desde 1967, cuando comenzó la reforma agraria, la fuerza pública, Carabineros, debió apoyar la reforma en vez de condenar o reprimir a la subversión. En la mente de la derecha, el sistema tenía protecciones que iban a impedir que Allende ganara. Por eso, lo que ocurrió el 4 de septiembre fue un shock emocional, porque lo imposible sucedió y, como escribió Jorge Arrate en un libro, se vivió "un tiempo inverosímil". La UP fue un tiempo increíble, inverosímil.

El triunfo de Allende convenció a las derechas de que los instrumentos institucionales habían sido insuficientes para impedir que Allende y las izquierdas marxistas ganaran una elección presidencial. Por eso en la Constitución del ochenta las derechas buscaron impedir que una institucionalidad, como la que plasmó la Constitución del 25, diera lugar a una experiencia de izquierda. Entonces, el shock frente al triunfo de Allende sintetizó una serie de emociones, de miedo, miedo a las estatizaciones, a la expropiación de los latifundios. No obstante, el triunfo de la UP también implicó un fracaso. Las derechas del Partido Nacional, gremialistas y nacionalistas se levantaron como alternativa política con Jorge Alessandri en 1970 y fracasaron, entonces estaban dispuestas a hacer cualquier cosa para evitar que Allende tuviera éxito.

La UP y Allende se enfrentaron a un enemigo que hizo diagnósticos feroces sobre el siglo XX. No es que la derecha descubriera que la Constitución del 25 y lo que había pasado desde el 38 era un problema, lo tenían clarísimo en 1920, en 1925 y en 1938, pero desde 1970 tuvieron que enfrentarse al desafío de una 
institucionalidad que había legitimado la presencia marxista, abrió el sistema para que se convirtieran en gobierno, pero no permitía detenerla. A pesar de que se unió con la DC para aprobar algunas acusaciones constitucionales, las derechas no lograron destituir a Allende ni parar el proceso de creación del Área de Propiedad Social, ni parar las movilizaciones, apelando a la institucionalidad. Entonces, llevaron al paroxismo una movilización que deslegitimara tanto a las instituciones como a la representación que Allende y la UP hacían de la democracia y de los valores y derechos populares y ciudadanos. Fueron derechas que dieron la pelea en todos los planos y formaron una alianza que se propuso el golpe militar cuando ya no había otras alternativas para detener el proceso socialista. Al principio, solo la derecha fascista, nacionalista, planteaba que las FF.AA. tenían que tener una función política, la derecha tradicional conservadora nunca planteó eso. Sin embargo, a fines de los sesenta, todas las derechas evolucionaron hacia un cambio doctrinario, en el cual la institucionalidad chilena no se afirmaría solo en los factores políticos, sino que se le daría un papel fundamental a las FF.AA. Si la institucionalidad nueva no era capaz de impedir que los subversivos se tomaran el control del poder, finalmente tendrían que contar con la herramienta de la fuerza incrustada en la propia institucionalidad.

Aunque esta lucha respondía, fundamentalmente, a un conflicto interno, el factor internacional fue crucial, porque las derechas nada podían hacer sin la ayuda de Estados Unidos, que les entregó ingentes recursos.

Francisco Figueroa: gracias, Verónica. Eso sirve como puente para plantear que quienes intentaron mover al gobierno de la UP no respondían solo a intereses domésticos. Peter, quizá tú puedes iluminar un poco esa variable y aportar a esa pregunta.

Peter Winn: me parece muy apropiada mi tarea, como norteamericano, de explicar el rol de los Estados Unidos. El gobierno de los Estados Unidos miró a las aspiraciones chilenas en el marco de la Guerra Fría. Eso fue fundamental. Su importancia fue mayor para Henry Kissinger por el eurocomunismo que estaba de moda en Europa en aquellos años, y que fue muy parecido a la vía chilena de Allende. A Kissinger no le importaba tanto América Latina, pero sí Europa. El programa de Allende además resultaba una amenaza a los intereses económicos de Estados Unidos al nacionalizar las grandes minas de cobre. Fue un chileno, Agustín Edwards, el dueño de El Mercurio, quien convenció a Kissinger y a Nixon de que tenían que evitar la asunción presidencial de Allende a toda costa. A partir de ahí nació una alternativa norteamericana con dos vías paralelas: la primera vía era el golpe de Estado legal. Como Allende había obtenido el porcentaje mayor de votos, pero no la mayoría absoluta, el Congreso debía elegir entre Allende y 
Alessandri, los dos candidatos más votados. Alessandri propuso un golpe legal en que la DC, que tenía los votos decisivos, votaría por Alessandri, que renunciaría, dando así oportunidad a una nueva elección, con lo que el ex presidente Eduardo Frei Montalva podría volver a ser candidato y resultar electo con el apoyo de la derecha. Pero Radomiro Tomic, el candidato presidencial de la DC, reconoció el triunfo de Allende y entonces la DC puso como condición para aceptar el triunfo de Allende que la UP aceptara ciertas garantías constitucionales, confiando en que Allende las rechazaría. Pero Allende las aceptó y eso preparó un escenario en el que la DC tendría que votar a favor de Allende en el Congreso, poniendo fin a la primera vía norteamericana. La segunda vía era el golpe de Estado militar, con un complot oscuro dirigido por la CIA, pero con la participación de militares y paramilitares chilenos. El complot contempló el secuestro del comandante en jefe del Ejército, René Schneider, un constitucionalista que consideraba que las FF.AA. no debían intervenir en política. Schneider se resistió a ese entuerto y terminó muerto. Fue un asesinato tan brutal en un país que, en el año 1970, todavía no estaba acostumbrado a la violencia política. Desde ahí en adelante los Estados Unidos trataron de socavar a su gobierno, sobre todo a través de un bloqueo financiero invisible. que dejó al gobierno de la UP sin los préstamos y las líneas de crédito que una economía de exportación como Chile requería. Luego, los Estados Unidos propiciaron las condiciones para el golpe militar.

Pero sería un error señalar a la clase alta chilena como meros secuaces del imperialismo yanqui. Como Verónica subrayó, las élites chilenas siempre han sabido cómo defender sus intereses, tal como lo hicieron con el gobierno de Eduardo Frei Montalva, contra la reforma agraria. En el caso de la vía chilena al socialismo de Allende, los grandes capitalistas y latifundistas se opusieron a las aspiraciones del pueblo y lograron arrastrar con ellos a la pequeña burguesía, asustándola con la mentira de que la UP iba a estatizar sus pequeños negocios y propiedades. Esto llevó a que la pequeña burguesía se tornara contra la UP y que esta perdiera, como consecuencia, las elecciones parlamentarias. El resultado de las elecciones del año 1973 fue un empate: la oposición como alianza del centro y la derecha ganó, pero sin los dos tercios necesarios para sostener una acusación política. Es decir, el resultado fue un empate político polarizado que las FF.AA. romperían con el golpe militar del 11 de septiembre de 1973 y la dictadura cívico-militar que duró 17 años.

Francisco Figueroa: gracias, Peter. Jorge, a ti te tocó enfrentar, desde el gobierno, estos intereses que Verónica y Peter han descrito. De hecho, lideraste uno de los procesos que más resistió la élite. ¿Qué puedes aportar a la discusión sobre este punto? 
Jorge Arrate: la verdad es que la nacionalización del cobre fue una idea que se construyó a lo largo de todo el siglo, partiendo por Recabarren, pasando por el PC, por Grove, por la República Socialista, la fundación del PS y luego por el momento registrado en una fotografía, muy bonito: en la década de los cuarenta, dos senadores comunistas fueron declarados fuera de la legalidad. Todavía eran senadores porque no podían despojarlos de sus senadurías, pero iban a terminar en campos de concentración. Salvador Ocampo y Elías Lafertte, que había sido secretario general del PC, le entregaron un proyecto de nacionalización del cobre a finales de los años cuarenta a otro senador para que lo hiciera suyo en el Senado, ya que ellos no iban a poder; ese era Salvador Allende. Esa idea fue como una bola de nieve, tuvo apoyo de los trabajadores, de los grandes sindicatos, las huelgas de los trabajadores del cobre tenían siempre como punto fundamental recuperar esa riqueza para Chile. Se transformó en una idea hegemónica a tal punto que las propias élites más recalcitrantes tuvieron que disfrazarse. Que nadie crea que esta es la primera vez que la derecha se disfraza y dice que está a favor del Apruebo. Gente como Pablo Longueira, ya en el año 70, 71, votaron a favor de la nacionalización del cobre porque fue unánime en el Congreso pleno la reforma constitucional.

Quiero ir un segundo más atrás y complementar lo que ha dicho Peter. Esta es una hipótesis, yo no soy historiador, es una idea, pero yo creo que Allende, antes de la revolución cubana, fue una cosa para los Estados Unidos, y después de la revolución cubana fue otra. El Allende del 52 y del 58, a punto de ganar, tenía otra cara, pero viene el $1^{\circ}$ de enero de 1959 y el impacto de la revolución cubana en la izquierda chilena. El 64, Allende tenía otra cara, la izquierda se había consolidado, la revolución cubana había modificado el mapa geopolítico. En el 70 la amenaza era mucho más clara: Cuba, a pocas millas de Estados Unidos, había proclamado un Estado socialista y ahora, en el sur, a través de una vía no armada, Allende repetía la frase "a la violencia reaccionaria, la violencia revolucionaria", y no era pura retórica. Allende apoyaba a otros movimientos revolucionarios en América Latina que estaban o habían estado embarcados en la guerrilla, en el foco de la lucha armada, hay ahí una sutileza que no quisiera dejar escapar. Esta vía no armada ponía ciertamente en riesgo a Estados Unidos.

El punto central no es tanto la nacionalización del cobre como la fijación de las compensaciones con la nacionalización. No querían la nacionalización porque ganaban muchísimo dinero con las minas chilenas. Allende tenía que dictar un decreto para fijar cuánto eran las utilidades excesivas, completamente polémico; hoy sería "deschavetado", pero ese era otro mundo. En ese mundo, era legítimo que un país que recuperara sus riquezas pagara una compensación, que es lo que Chile iba a hacer, descontando de esa compensación aquello que había sido excesivo. Entonces se aplicó a esas empresas un impuesto retroactivo, usando el criterio de las utilidades 
excesivas, y fue eso lo que suscitó una verdadera batalla legal, jurídica, comercial con los Estados Unidos, que se agregó al flujo de dinero que desde la mitad de los años sesenta había entregado la CIA y otras organizaciones para financiar a la derecha o a todas las organizaciones que querían derrocar a Allende. Eso no lo inventó ningún izquierdista, eso está establecido en el Informe Church, que lleva el nombre de un senador norteamericano y que tiene dos tomos de documentación y se hizo en los años setenta, ahí está toda la información sobre la intervención que hizo el gobierno de Estados Unidos en Chile y, particularmente, aquella contra el gobierno de Allende. En el capítulo octavo de las memorias de Kissinger, Nixon le dice a Kissinger: "Haga chillar la economía, haga gritar, haga llorar la economía".

Francisco Figueroa: gracias, Jorge. María Isabel: ¿cómo crees que la izquierda enfrentó esta arremetida de la derecha y de los poderes económicos durante la UP?

María Isabel Matamala: el gobierno norteamericano, junto con la burguesía chilena, planeó esta campaña del terror que buscó amedrentar a todo el pueblo y que tuvo un sesgo en particular contra las mujeres que me parece importante destacar. El candidato Alessandri asumió una estética y un discurso patriarcal para lograr la adhesión femenina, demonizando a Allende, y toda esa campaña del terror fue coordinada por dos organizaciones sociales de la derecha, Acción Mujeres de Chile y Chile Joven. Autoras han señalado que toda la propaganda hacia las mujeres reveló una comprensión muy refinada para usar el enfoque de género en una elección presidencial. Los medios La Tercera y El Mercurio convocaban a las mujeres a votar, como madres, por Alessandri, y colocaban una consigna: "las madres saben que el mañana de sus hijos — ahora diríamos hijos, hijas e hijes— se decide hoy". Esa era la consigna que se repetía. Los intereses empresariales eran dirigidos por el gran capital nacional y extranjero, con una amplia base de la pequeña y mediana industria, las FF.AA., los medios empresariales, especialmente El Mercurio, desde donde Agustín Edwards coordinó y dirigió, como bien dijo Peter, los intereses del empresariado, usando todos los medios de lucha contra el gobierno de Allende. Aquí está el cinismo de la derecha cuando critican el "todos los medios de lucha". Antes de que Allende asumiera la presidencia, lo hicieron mediante la desestabilización, el asesinato de Schneider, como ya lo mencionaba Peter, el desabastecimiento, los atentados terroristas a la infraestructura y el sabotaje contrarrevolucionario. Los discípulos aliados para concretar la utopía neoliberal convocada por Hayek fueron los egresados de la Escuela de Chicago, los grupos económicos y la Armada. Todos ellos concordaron en la necesidad de un golpe que arrasara con el mundo político y social, para, en ese páramo, construir un proyecto mercantilizador de la vida, asentado en el terror de un gobierno autoritario militar. 
Francisco Figueroa: gracias, María Isabel. Ahora les quiero proponer que nos pongamos en otra dimensión conflictiva de la UP, la que tiene en su interior la izquierda y también el movimiento popular, con toda su diversidad. ¿Cuán relevantes fueron las tensiones del gobierno de la UP en su desenlace y cómo las enfrentaron los diversos protagonistas que estaban a cargo de este proceso? Jorge, te propongo que comencemos esta parte contigo.

Jorge Arrate: partiría diciendo lo siguiente, para ser claro y no ocultar mi visión: yo creo que es un mito que haya revoluciones sin tensiones, es parte de cualquier proceso revolucionario. La UP fue parte de un proceso revolucionario, es el único momento, en más de dos siglos de historia republicana de Chile, en que hay una voluntad seria y radical de cambiar el signo del poder, con un apoyo de masa muy sustancial. No es el 38 por ciento de apoyo, porque meses después obtuvimos más del 50 por ciento en las elecciones municipales y eso hay que considerarlo.

Se dice que faltó una dirección única. Sé que es polémico lo que estoy diciendo, pero tengo un cierto cuidado con las direcciones únicas, tiene que haber una dirección, pero hay distintas maneras de hacerlo. La dirección única, en realidad, la ejerció, durante los tres años, durante los mil días de la UP, el presidente; Allende tomó las decisiones finales. Ahora, ¿'en qué terreno tuvo que moverse? Había un segmento que adscribía a la dirección política, que era el PC, que tendía a identificarse con una forma más pausada de enfrentar el proceso y que respaldaba al presidente Allende en todo lo que era el manejo de las Fuerzas Armadas. Después había un sector, que estaba fuera de la UP, que era el MIR y que tenía influencia mayor más allá de que eran minoritarios en términos numéricos- y que era fronterizo con miembros socialistas y cristianos revolucionarios que tenían, en cambio, la idea de que había que ir más rápido y que había que golpear con más fuerza al poder militar, que estaba presto a hacer un golpe. En el centro estaba, yo creo, la mayoría del PS, más inclinado hacia Allende, con un secretario general como era Carlos Altamirano, a quien se le ha culpado de muchísimas cosas, pero que lo que hacía era tratar de mediar entre diferentes sectores. Allende era un hombre tremendamente democrático, tremendamente respetuoso de los partidos, y tuvo dificultad para alcanzar una opinión en algunos momentos, porque el debate se hizo muy difícil en las cúpulas. En la base se generaron procesos que suscitaron bastantes dificultades internas, me estoy refiriendo a la generación de los cordones industriales, de la unión de cordones, de la participación política y de la conducción política a nivel de las empresas y de núcleos de empresas que tuvieron fricciones con lo que era el sindicalismo establecido. Los grandes sindicatos no estaban habituados a la participación que se estableció en las grandes empresas, como en la del cobre. Se constituyó un directorio en todas las empresas nacionalizadas, donde había cinco 
representantes del dueño, del gobierno, el Estado; cinco representantes de los trabajadores electos; y el presidente, designado por el presidente de la república. Los grandes dirigentes sindicales sintieron preocupación por la emergencia de estos nuevos directores, porque entendían que podía haber algunas figuras que hacían una competencia. Es cierto que el proceso no tuvo una conducción uniforme, única, se vivía en un debate, porque era un proceso revolucionario, un conjunto de reformas que fueron hechas unificadamente y que cualitativamente constituían una revolución. Creo que el tema se ha exagerado en el análisis político que se ha hecho del periodo.

Francisco Figueroa: gracias, Jorge. María Isabel, ¿también crees que el análisis se ha exagerado? A ti te tocó vivir esta experiencia desde una izquierda que tenía una visión distinta sobre la conducción. Cuéntanos.

María Isabel Matamala: también concuerdo en eso de que las diferencias en el seno de la izquierda, de la UP, se arrastraban en el tiempo y convivieron durante décadas. Estas se resumían en una estrategia que buscaba concretar reformas graduales que dieran cuenta del proyecto programático en marcha y otras que pretendían acelerar y profundizar el proceso, con el objetivo de impedir o retrasar la recomposición total de los sectores dominantes. También existió una divergencia referida al protagonismo del pueblo, pues en un caso se priorizaba la movilización y el apoyo electoral y, en el otro, la profundización de la actoría social y política del pueblo para asegurar la construcción de poder popular capaz de sostener al gobierno, ejercer control social y velar por la iniciativa de la producción, la defensa y protección frente a los sabotajes de la clase dominante y sus partidos. Otra de las tensiones que ya esbozaron aquí fue la relación con las Fuerzas Armadas. Un sector mayoritario confiaba en el constitucionalismo de las FF.AA., basándose en su relación con algunos oficiales y altos mandos cercanos y en el respeto que habían demostrado a través del tiempo por la Constitución. Desde otra mirada, sectores de la UP compartían con el MIR la certeza de la necesidad de un trabajo político al interior de las FF.AA., que cooptara las tropas, los suboficiales, los oficiales y los clases $^{2}$. Este trabajo fue descubierto al interior de la Armada e implicó una fuerte represión sobre los marinos. Otra divergencia fue aquella en torno a la necesidad o no de prepararse militarmente para enfrentar el golpe cívico-militar que más tarde o más temprano tendría lugar. Está claro cuál fue la opción que dominó, pero en el caso del MIR y su oposición crítica, nunca se dejó de dialogar con Allende,

2. Escalafón militar que agrupa a cabos y sargentos. 
incluso en el marco de la tragedia del 11. En su última conversación con Miguel, Allende le dice que llegó su momento. Siempre fue una relación de fraternidad, de diálogo permanente, y yo diría que en mil días era difícil consolidar una unidad con una diversidad tan amplia de toda la UP y el MIR, y más difícil o imposible era una estrategia entre pactos y acuerdos entre el allendismo y la DC, porque eso iba a significar, sin duda, la división de la izquierda. Pienso que las divergencias, en general, fueron tratadas de la mejor manera posible en ese momento.

Francisco Figueroa: gracias, María Isabel. Quisiera pedirles a Verónica y a Peter que también se refirieran a esto, sobre todo desde el punto de vista de las tensiones entre populismo y Estado. Había una doble tarea: organizar al pueblo y conducir un Estado para realizar las reformas que se iban a implementar. Peter, tú has trabajando mucho este tema. ¿Qué nos puedes contar?

Peter Winn: antes de eso, la época de la UP no solo fue una era de sueños y anhelos cumplidos, también estuvo llena de conflictos; esto se dio incluso entre los que formaban parte de un mismo bloque político. En el análisis de los conflictos de la época de la UP se pone énfasis en los conflictos políticos, partidistas e ideológicos, pero el conflicto que más me interesó fue entre "la revolución desde arriba" de Allende y sus asesores, y la "revolución desde abajo" de los trabajadores, campesinos y pobladores, que tomaron la revolución en sus propias manos y, al hacerlo, la materializaron.

Avanzando "la revolución desde abajo" con la toma de su fábrica, los trabajadores de Yarur creían que estaban promoviendo el proceso revolucionario de Salvador Allende y cumpliendo su promesa de estatizar la empresa para que pertenezca a sus trabajadores y al pueblo de Chile. Pero en vez de tener el apoyo de Allende, este trató de frenarlos en su intento de tomar la fábrica y de frenar la estatización, argumentando que era prematuro, que estaba fuera de la secuencia prevista y que, más aún, le correspondía a él y no a ellos de dirigir el proceso revolucionario; él era el presidente y él debía decidir el cuándo, el cómo y el qué del proceso revolucionario, no los trabajadores. Para Allende, la vía chilena era un camino difícil y estrecho que solamente sería viable mientras estuviera cuidadosamente trabajado, coreografiado y controlado desde arriba. Por lo tanto, la "revolución desde abajo" de los trabajadores de Yarur y otros amenazaba su control del proceso revolucionario. Lo que fue clave para la estrategia de Allende fue no perder el apoyo o por lo menos la neutralidad de la clase media. Al mismo tiempo, tuvo que satisfacer las necesidades básicas del pueblo y avanzar por la vía chilena hacia el socialismo democrático. Como explicó Allende a los trabajadores de Yarur, su "revolución desde abajo" planteaba cuestiones fundamentales sobre cómo tenía que ser la condición revolucionaria, y la 
espontaneidad de los trabajadores amenazaba el éxito del proceso que él conducía. "Las masas no pueden sobrepasar a los dirigentes", les dijo Allende, porque estos tienen la obligación de dirigir y no dejarse dirigir por las masas. Pero, en última instancia, Allende no podía arriesgar un conflicto con los obreros industriales, su base central, sobre la estatización de Yarur.

Los dirigentes sindicales tenían razón en cuanto a que la dinámica local había llevado a los trabajadores de Yarur a tomarse la empresa y pedir su estatización, y no podían dar marcha atrás sin destruir ese movimiento. Pero Allende también estaba en lo cierto cuando les dijo: "si les doy el visto bueno a esta, va a venir otra, otra y otra, porque ya se me arrancó una". Y eso fue lo que pasó, empezando con las otras fábricas del sector textil. Como consecuencia, Allende y su "revolución desde arriba" perdieron el control de los tiempos, las fases, las secuencias y las narrativas de los procesos revolucionarios, y los conflictos con la alianza de centro-derecha por las tomas y las estatizaciones se agudizaron tanto que, desde la perspectiva de la oposición, facilitaron la interpretación de que Allende y su gobierno estaban fuera de la ley.

Para tener éxito, "la revolución desde arriba" y la "revolución desde abajo" debían avanzar juntas, como pasó durante el paro de octubre de 1972, cuando la "revolución desde abajo" con sus cordones industriales fraguó el proceso. Pero en el Chile de la UP no se logró resolver nunca el conflicto entre la "revolución desde arriba" y la "revolución desde abajo", un conflicto que paralizó a las dos. Y por eso, al final, cuando se produjo el golpe del 11 de septiembre, los militares encontraron muy poca resistencia, una sorpresa para ellos.

Francisco Figueroa: gracias, Peter. Verónica, ¿cuál es tu mirada sobre los conflictos de la UP y cómo comprometieron esta revolución?

Verónica Valdivia: hubo conflictos entre las izquierdas, porque había miradas distintas, la idea de una revolución por arriba —institucionalizada—, como la emergencia de una revolución por abajo. Sin embargo, eso es propio de procesos revolucionarios, las revoluciones desatan acciones que no están planificadas ni entran en un programa específico. La revolución es la vida y tiene sus facetas hermosas y sus facetas feroces y, en el caso de Chile, Allende y la UP se jugaron por una vía institucional y no armada. La izquierda tomó este camino muy tempranamente, desde Recabarren, a comienzos del siglo XX y en adelante. Mientras los ácratas pensaban que la lucha era entre los patrones y los trabajadores, Recabarren planteaba que había una dimensión política, muy importante de defender; había que disputar el poder. La lucha no transcurría solo en las unidades productivas, sino que había que disputarlo en todos los planos políticos. Esa noción de Recabarren y de la 
izquierda chilena hizo posible la UP. La UP es una hija del siglo XX, de la decisión de la izquierda de insertarse en el sistema político y luchar desde adentro. Lo que ocurrió durante la UP fue la materialización de esa revolución, de esos sueños que eran imposibles en 1912. Pero, las revoluciones no son procesos que puedas controlar. Las divisiones al interior de la UP, las tomas de tierras que Allende no quería apoyar sirvieron a los opositores para movilizar apoyos contra la UP y hacerla perder fuerza social, apoyo de las clases medias, segmentos importantes. También es relevante decir que no todo el pueblo estaba con la UP, la derecha fue capaz de movilizar sectores populares en las poblaciones, fue capaz de movilizar, pequeños comerciantes, pequeños industriales que temían la expropiación, aunque no estaban dentro de los planes de expropiación del gobierno. No era la primera vez que la derecha, los grandes empresarios, movilizaban a los pequeños; lo hicieron contra las leyes sociales en 1920, en 1925, en 1926, solo que esta vez tuvieron los recursos desde Estados Unidos para paralizar durante un mes a los camioneros. ¿Quién los iba a financiar un mes? Bueno, en el Chile de 1973, los recursos estaban y lograron movilizar los miedos y los fantasmas del anticomunismo inventados durante el siglo XX. El anticomunismo no solo en contra del PC, el anticomunismo como una forma de deslegitimar y criminalizar a todos los que piensan distinto y se movilizan por objetivos diferentes al orden capitalista. Este pensamiento anidaba no solo en la derecha, sino también en sectores católicos, en pequeños grupos de clase media y baja. La derecha logró movilizar esos miedos y esos odios que venían de un pasado que se había ido consolidando.

Me parece importante decir que gran parte de las disidencias de la UP se debieron a que Allende se negó a reprimir. Es decir, ¿qué tenía que hacer para evitar las tomas? Ir con las FF.AA. y reprimir a los obreros o hacer una zona de emergencia para detenerlas. Eso es lo que habían hecho todos los presidentes, pero Allende se negó, no lo hizo, y esa era la acusación que la derecha le lanzaba de violar el Estado de derecho, que reclamó cuando se produjo la toma de la fábrica Yarur. ¿Por qué no fue con la fuerza pública a sacar a los trabajadores de ahí? Porque, como dijo Arrate, Allende sí creía en la democracia, en la posibilidad de la disidencia y en la negociación, y se negó a usar el aparato coercitivo del Estado. Allende no era un soñador, él no se negó hacer esto porque abandonara la realidad. La vía chilena, ¿por qué fue posible? Porque los factores políticos fueron siempre preeminentes, en Chile no hubo una opción armada en 1925 ni en 1932 ni en 1948, cuando Gabriel González armó un campo de concentración. Los factores políticos fueron siempre importantes y estuvieron en el horizonte de Allende.

Francisco Figueroa: gracias, Verónica. Esta ha sido una conversación muy enriquecedora, pero como todo diálogo, hay que empezar a cerrar. Quisiera 
proponerles que nos cuenten, en dos palabras cada uno de ustedes, cuál creen que es el legado que nos deja la UP y que ustedes creen que es necesario rescatar. María Isabel, partimos contigo.

María Isabel Matamala: hay muchas cosas que rescatar, pero vamos a hacerlo corto. La originalidad política de la primera experiencia histórica amplificada para intentar construir un Estado de derecho y con justicia social, con un anclaje social, con un compromiso con el conjunto del pueblo, a pesar de las discrepancias de las que hemos hablado. El respeto de Allende por los derechos humanos, no usar la represión, su fuerza cultural y su ética política. Pero, sobre todo, a pesar de las distintas interpretaciones y de que no estuvimos de acuerdo en su momento, la noción, que se fue fortaleciendo, del poder popular territorial de abajo hacia arriba, independientemente del gobierno, pero con el gobierno como aliado en la construcción de un país compartido. El poder popular como fuerza social amplia o programática, todo ello necesario para hacer posible otro modelo humano con algo que fue un aporte fundamentalmente de Allende, pero también del conjunto de la UP: la voluntad política con un horizonte y una alternativa programática que estableció con claridad su profunda diferencia con el sistema dominante, en crisis en ese momento.

Francisco Figueroa: gracias, María Isabel, muy buena síntesis. Peter, ¿qué nos puedes decir sobre el legado de la UP?

Peter Winn: hace pocos años atrás estuve entrevistando a líderes estudiantiles para mi libro La revolución chilena, sobre el legado de la UP para los activistas de hoy. Y un dirigente estudiantil de la FECH, que se llama Francisco Figueroa, me dijo que la lección de la UP para la actualidad es "que el pueblo como tal tiene que ser el protagonista de su historia y no intermediarios como los partidos políticos". Es un gran legado y, además, hay que resistir los esfuerzos de los líderes sindicales y sociales de controlar el movimiento, esas son cosas que se ven en los últimos años, en los movimientos de 2019, sobre todo. Otro legado de la UP está en la cultura popular. Me llamó la atención que muchas de las canciones que se escuchaban y se siguen cantando en la Plaza de la Dignidad corresponden a la música de la época de la UP, sobre todo, la música de Víctor Jara, un cantante que no sobrevivió a esa época y que, por eso, ha quedado asociado por siempre con el período. Los sueños que estaban reflejados en esa cultura quedaron para siempre. Estuve con las feministas en su marcha de 2020, su marcha millonaria del $8 \mathrm{M}$, justo antes de que la pandemia cambiara el panorama, y la creatividad del pueblo, de la que también me habló ese Francisco Figueroa, fue extraordinaria. Cuando Chile salga de la pandemia, cuando 
cambie el enfoque a su nueva Constitución, va a tener los sueños de la UP como recurso y los conflictos de la UP como advertencia.

\section{Francisco Figueroa: ¿Verónica?}

Verónica Valdivia: diría que el principal legado es la creencia de que los seres humanos pueden cambiar para bien, a diferencia de Guzmán y los gremialistas, que creían que la naturaleza del ser humano es intrínsecamente mala. Allende creía que era posible construir un ser humano nuevo, mujeres, hombres distintos, solidarios, fraternos, y construir una sociedad con esos valores. Eso fue lo que destruyó la dictadura. La dictadura enfatizó los peores valores y adhirió a las peores causas, trabajando para transformar a las/los chilenas/os en átomos individuales que solo se deben a sí mismos, cortando toda solidaridad y convirtiéndonos en seres competitivos y rivales. La UP tenía otros sueños, sueños de que era posible la fraternidad humana y que íbamos a llegar a un acuerdo para construir esa sociedad en la medida en que los seres humanos se convirtieran en lo que en ese momento se llamó el hombre nuevo — sin duda, estaba pensado sin sentido de género—-, para construir una sociedad mejor. Creo que eso es un gran legado.

Francisco Figueroa: gracias, Verónica. Jorge, tienes la palabra ahora.

Jorge Arrate: el otro día, alguien, en uno de los Zoom a propósito del 4 de septiembre, me preguntó: "bueno, ¿necesitamos otro Allende?" Yo le dije: "Allende hay uno solo”. No sé qué responder a esa pregunta. Él no fue ni calco ni copia, lo he repetido en estos días muchas veces, la frase de Mariátegui, porque la UP fue en un tiempo, Allende fue un hombre de su tiempo, no es un personaje histórico, y ese tiempo fue hace cincuenta años. Todas las cosas que han ocurrido en estos cincuenta años hay que ponerlas por delante y analizarlas, y ver cómo lo hacemos de aquí en más. A mí me cuesta hablar de lecciones de la UP, pero sí puedo hablar de legados, inspiraciones que produce la UP, y hay muchas; yo me quedo con uno de los Allende, hay varios Allende. Hay uno, que era el militante socialista, que, para mí, en la época en la que milité en el PS, hace ya algunos años, fue muy interesante. Hay un Allende que es el Allende utópico, el Allende soñador. Yo tomé una cierta distancia cuando, a los 100 años de su nacimiento, el énfasis se puso en eso. ¿Por qué tomé distancia de ese Allende? Porque todos soñamos todos los días, yo sueño casi todos los días, cosas que tienen bien poco sentido a veces. Allende no fue un soñador, Allende fue el jefe de un proyecto político revolucionario, tenía un horizonte, tenía principios, tenía criterios y, como todos los grandes líderes, se sumergió a fondo en las grandes contradicciones y opciones que se le presentaban. 
Cuando les dijo a los trabajadores de Yarur: "mira, el que manda soy yo", la verdad es que me imagino que Lenin, Marx, Castro hubieran dicho lo mismo si les hubieran ido a plantear una cosa parecida, porque los líderes tienen que tomar resoluciones y adoptar posiciones, y a veces se equivocan, pero tienen esa obligación. Yo me quedo, como herencia, con ese Allende del discurso del Estadio Nacional en que despidió a Fidel Castro después de su visita a Chile y dijo: "yo no soy un mártir, yo no soy un redentor social, yo soy un ser humano, un simple ser humano que ha asumido una tarea, que cree que su deber es luchar por el pueblo y sus intereses".

Francisco Figueroa: gracias, Jorge, muchas gracias por estas palabras. 